\title{
Métodos de Treinamento e sua Utilização (*)
}

\author{
Tomás de Vilanova Monteiro Lopes
}

\section{F cussão em grupo, salienta os seguintes aspectos:}

1. O participante aprende mais porque é treinado para pensar por si mesmo. Não encontra as soluções prontas ou os principios estabelecidos, como na leitura.

2. O pensamento do grupo é mais produtivo que o pensamento individual. A contribuição de um só hocia. No grupo cada participante deve ter alguma coisa para oferecer aos outros; assim, a base da aprendizagem ganha mais largueza.

3. A discussão estimula cada pessoa presente a expressar livremente suas idéias. Noutras palavras, uma atmesfera "permissiva" é criada e, dentro dela, cada um se sente incentivado a esclarecer seu próprio pensamento e a ponderar, cuidadosamente, as afirmações dos outros.

4. O participante ao retornar ao trabalho sente-se mais inclinado a pôr em prática o que aprendeu.

Há vários tipos de discussão em grupo. Os mais conhecidos são o seminário, o simpósic e o forum.

Destinado à, treinamento do mais alto nivel, o seminário é uma reunião de pessoas possuidoras de conhecimentos especializados em determinado assunto; nêle se reúnem a discussão e a pesquisa, send; ambas exercidas com inteira independência pelos membros do grupo, de modo que as conclusões finais se desenvolvem sôbre uma base de idéias e experiências representativas de um alto tirocínio na matéria. Forma de treinamento superior, o

(*) A primeira parte dêste ansaio foi publicada no vol. $91 \mathrm{n}^{\circ{ }^{\circ}} 1,2$ e 3, de nossa Revista. 1959.

(9) Public Fersonnel Administration - Henry Holt Co. - New York, 
seminário, quando usado por principiantes ou aplicado a assuntos gerais que ensejem a livre tomada de posições meramente opinativas, revela-se pouco fecundo. Só se deve esperar que produza resultados compensadores quando as pessoas que dêle participam são especialistas consumados no assunto em discussão. (10)

Enquant.) o seminário exige que os membros do grupo guardem entre si uma certa unidade, ou pelo menos grande afinidade de especializaçãc. o simpósio reclama que possuam diferentes especializações sôbre o mesmo assunto, afim de que êste possa ser estudadı, conı proficiência, dos diferentes pontos de vista que lhe dizem respeito. Cada membro do simpósio deve ter conhecimento especialızado num aspecto do assunto em causa. A soma das contribuições individuais ensejará a compreensão global do assunto, com os diferentes ângulos dêste último apreciados pelo critério da especialização.

U forurn é uma discussão que se estabelece em tôrno de temas controvertidús, deixandomse aos que dêle participam a faculdade de exprimir, livremente, suas opiniões. A liberdade de uso da palavra e a franquia ac fluxo das idéias e reações dos membros do grupo constituem a caracteristica fundamental do forum e, também, a causa de suas principais deficiências. Numa discussão dêsse tipo é extremamente difícil manter-se uma atmosfera de método e de ordem, e evitar - se a digressão na qual se malbarata a maior partz do tempo.

\section{A LEITUIRA ORIENTADA}

A leitura é um método de treinamento pouco dispendioso, mas que pode produzir bons res ltados, quando usado criteriosamente, sobretudo em associação com outros métodos.

Para determinados tipos de aprendizagem, como os que exigem a apreensão de grande quantidade de fatos ou informações, que tornam indispensável a utilização de seqüências verbais e elementos sistematizados; que reclamam a análise atenta, minuciosa e reiterada das premissas de uma conclusão ou do desenvolvimento de um raciocinio; que implicam na revisão e comparação de idéias diferentes ou das diferentes fases de uma mesma idéia; enfim, em todos os casos em que a aprendizagem se alimenta principalmente de fatôres abstratos que envolvem descrições, definições e teorias, a leitura é de importância inexcedivel. Como a observação ela possibilita a aprendizagem sem que seja indispensável a presença do professor; e, sob tal aspecto, supera a observação,

(10) Milton Hall, op. cit., pág. 80 . 
pois que esta é mais limitada, menos versátil e, em geral, menos disponível. Nem sempre nos é dado observar aquilo que desejamos aprencier, e nem sempre as oportunidades de observação satisfazem as nossas necessidades e os nossos interêsses. Ainda que não se considere o autodidatismo a melhor forma da aprendizagem, não se pode deixar de reconhecer que êle é, muitas vêzes, a única forma possivel de aquisição do conhecimento e da modificação da conduta. Bastaria êsse fato para demonstrar o que a leitura representa como método de treinamento.

O livro é, por assim dizer, uma escola em miniatura, à qual o aluno pude recorrer sem subordinação a horários ou a formalidades rígidas; em qualquer tempo e em qualquer lugar em que se sinta ruotivado para a aprendizagem, o aluno terá o livro a seu dispor e poderá utilizá-lo até que sobrevenham o cansaço e o desinterêsse. A anrendizagem torna-se, assim, mais espontânea. Alér disso, a grande variedade dos textos comumente disponiveis facilita a adaptação da aprendizagem às características pessoais do aluno.

A leitura tem as suas desvantagens. A primeira delas é o isolamento a que pode relegar o aluno, e que impede, como já tivemos ensejo de observar a propósito dos cursos por correspondência, a formação do ambiente de aprendizagem caracterizado pela atmosfera de emulação, de trocas de idéias, de trabalho em equipe. Quando, porém, a leitura é usada em associação com outros métodos, o isolamento do aluno pode inclusive constituir uma vantagen e não uma desvantagem, de vez que propicia a reflexão e o trabalho metódico e pessoal. Em tais casos a leitura age como um corretivo aos defeitos de outros métodos, nos quais o individuc fica inteiramente exposto ao domínio do grupo ou de alguns de seus integrantes, e, muitas vêzes, impedido de assu mir uma atitude própria e consciente no progresso de aprendizagem. Se necessário, porém, o isolamento do aluno pode ser evitado com o emprêgo da leitura coletiva orientada. Nesta versão do método varias pessoas se reúnem para a leitura em comum, sob a orientação de $u m$ instrutor. Cabe a êste selecionar os texios, dirigir a leitura, tecer comentários, prestar esclarecimentos, ou promover debates e argüições, visando a fixar, em tôrno de determinados tópicos, o interêsse dos individuos que estão sendo treinados.

Outra desvantagem: a leitura ministra o conhecimento teórico que por si só não habilita o indivíduo como realizador. A aprendizagem que ela proporciona é, via de regra, incompleta e requer que se the adicione o conhecimento prático, mediante o contacto direti corn os problemas, as condições e as técnicas próprias da 
realidade profissional. Graças a isso, porém, a leitura pode contrabalançar as deficiências de certos métodos, como a demonstração e a observaçãe, nas quais a preocupação pelo conhecimento prático sói produzir uma aprendizagem automatizada, sem maiores considerações pelos fundamentos teóricos das coisas.

Requisito fundamental ao êxito da leitura como método de treinamento é uma boa seleção de textos. Êstes, além da relação que devem manter com o assunto específico em tôrno do qual o treinamento é ministrado precisam ser bem elaborados, quer quanto à forma, quer quanto ao conteúdo. $O$ valor do texto é tanto maior quanto mais sólida a autoridade do autor na matéria versada. Por êsse motivo convém que se dê preferência aos textos de autores de reputação já estabelecida, salvo quando para o treinamento a pesquisa de coisas novas ou o exercício da capacidade de apreciação ou de critica do trabalho alheio sejam indispensáveis ou pelo menos se recomendem com especial interêsse.

Ainda cor referência ì seleção dos textos há a observar que a apreensão do conteúdo dos mesmos deve depender, apenas, dos conhecimentos que os individuos que vão ser treinados já possuem ou poderi receber, fàcilmente, durante o treinamento.

\section{A SITUAÇÃO SIMULADA}

treinamento deve, em princípio, ser organizado em tôrno de situações reais, uma vez que é para estas que o indivíduo se prepara. A correlação positiva entre aquilo que se ensina, a maneira pela qual se ensina e as condições sob as quais vai ser aplicado o conhecimento adquirido constitui a pedra de toque da propriedade do treinamento. Mas nem sempre as situações reais podem ser tutilizadas, de modo direto, para fins de aprendizagem, seja porque dependem do fator acaso, porque ocorrem raramente ou não se apresentam com todos os elementos que as tornariam aptas ao trabalho didático, seja, enfim, porque envolvem graves riscos ou despesas de vulto. Os exemplos mais ilustrativos nesse particular sãc fornecidos pelos trabalhos de pesquisa, medicina (cirurfia, em especial), pela aviação, pelas operações militares etc.

O recursc, em tais casos é organizar o treinamento em tôrno de situaçôes simuladas, através das quais a realidade é reconstituída e adaptada às necessidades da aprendizagem. Fatos e experiências reais podem ser recompostos, graças à imensa variedade de recursos que o progresso põe hoje a serviço do ensino, e a sua apresentação, sob forma conveniente, possibilita um material de aprendizagem de boa qualidade. 
No treinamento de empregados, a situação simulada é, por assin dizer, uma função vicariante da situação real, e isto significa que ela deve aproximar-se o mais possivel da realidade. A imaginaçã', the é útil, sem dúvida, mas apenas para sugerir os meios mais apropriados à representação dos fatos e das condições em que os mesmos se desenrolam, jamais para alterá-los em sua natureza e significação.

Método de treinamento muito delicado, a situação simulada, em qualquer de suas variantes requer a contribuição de peritos dz grande proficiência no assunto a que diz respeito. Sòmente a tais pessoas se deve confiar a tarefa de orientar o preparo do material de ensino e regulamentar a maneira de aplicá-lo.

A situação simulada pode ser total ou parcial. Nesta última hipótese, toma-se uma situação real incompleta e a ela se adicionam os elementos que se fizerem necessários, a fim de torná-la adequada à finalidade didática em vista. Tudo se passa conforme o princípio de que só se deve recorrer à situação simulada, quando e na medida em que não fôr possível utilizar situações reais.

Na prática do método podemos simular:

a) a situação em vista da qual o treinamento se processa;

b) a posição que o indivíduo a ser treinado desempenha na situação; e

c) a situação e a posição do individuo.

A situação simulada embora não seja um método de treinamento novo (desde tempos imemoriais as fôrças armadas se servem do combate simulado para adestramento do comando e da tropa) ganhou, recentemente, a contribuição dos equipamentos eletrônicos, o que lhe possibilitou certas formas de apresentação mais requintadas, como, por exemplo, o "jôgo de emprêsas" (business game), no qual se reproduzem, para fins de treinamento, sobretudo de chefes e de dirigentes, as condições de trabalho numa organização, seus problemas e respectivas variáveis, e os dados a serem processados na tomada de decisões.

Tal requinte constitui, no entender de alguns autores, um perigo já que pode induzir a demasiado interêsse pelos meios em detrimento dos fins da aprendizagem. Perguntam êsses autores se o business game, ao invés de desenvolver a capacidade de chefia, nãı será, em realidade, apenas um meio de familiarizar o individuo com as técnicas de utilização dos dados elaborados pelos computadores eletrônicos. 
A conclusão de Merril Collet (11) é no sentido de que o jôgo per se não conduz à aprendizagem, pelo que devemos: a) encará-lo como uma técnica para nos familiarizar com as etapas a serem observadas na solução de um problema; e b) usá-lo não isoladamente, mas em conexão com a crítica daquilo que acontece! 1 durante o exercício da aprendizagem.

() utia modalidade do método da situação simulada é a dramatizaçăn, também conhecida sob as denominações de psicodrama e role playing. Consta da representação de uma fato ou incidente, na qual os participantes do processo de treinamento encaram os diversos personagens e reagem como tal, oferecendo à crítica do grupo as formas de conduta ou os problemas suscitados por aquêle tato ou incidente. É, pois, uma maneira de "viver" determinadas situaçôes e de reagir dentro delas, como seus personagens.

A dramatização oferece perspectivas muito interessantes ao treinamento em relações humanas. Dada a sua natureza ela se torna mais eficiente, como método de treinamento, quando cada pessua tem oportunidade de encarnar, no mesmo incidente, mais de uul dos personagens envolvidos, sobretudo quando a diferença das características e das posições de tais personagens fôr muito acentuada.

A pessoa encarregada da preparação de situações simuladas sugerinos que:

1. Organize os conhecimentos que possui a respeito da situação real, cuja simulação se pretende; para isso não confie, exclusivamente em sua memória; reveja com atenção os registros, relatćrios e anotações que houver.

2. Consulte outras pessoas cujos conhecimentos possam ajudá-lo, discuta com elas os pontos duvidosos e se possível obtenha novos dados para completar os seus.

3. Procure reconstituir a situação real com rigorosa objetividade, levando em conta todos os fatôres realmente significativos, como, por exemplo, as condições do ambiente, as caracteristicas das pessoas ou das coisas, a natureza dos processos, os tempos de duração e a seqüiencia das operações.

4. Examine como e enı até que ponto as circunstâncias atuais poderiam influir sôbre a situação real, se ela ocorresse agora, e procure neutralizar as que lhe parecerem capazes de alterar o conjunto de fatôres que deve ser preservado.

(11) Simulation As A Management Development Tool - in "Personnel Ad̛ministration", vol. $25 \mathrm{n}^{\circ} 2$ - Março-Abril de 1962. 
5. Quando der o seu trabalho por concluido, submeta-o a pessoa: credenciadas para criticá-lo com conhecimento de causa e independência.

6. Sempre que possivel ensaie a situação simulada que preparou, antes de apresentá-la aos alunos.

\section{O CASO}

\section{(case method)}

Os autores em geral, quando expõem os métodos de treinamento. costumam referir se ao método do caso ("case method"). Parece-nos que seria mais acertado considerar o chamado método do caso mais como uma técrica de coleta e preparação de material para análise, pesquisa e discussão, do que, pròpriamente, comi um método de treinamento. O caso, em si mesmo, pouco significa. O que lhe dá valor, para fins de treinamento, é a maneira de utilizá-lo, é a possibilidade que se tem de, em tôrno dêle, desenvolver no indivíduo que está sendo treinado uma atitude de pesquisa, de análise e de crítica, através da qual se aperperfeiçua a capacidade de apreender, de concluir e de exercer a imaginaçã') criadora, levando-se em conta e ponderando-se convenientemente os diversos fatôres de uma situação. Da maneira pela qual é comumente empregado, o caso, constitui, com raras exceções material para a discussão em grupo.

O chamado método do caso comporta algumas variantes. As mais cunhecidas são:

a) U caso é apresentado, sem qualquer comentário ou solução, deixando-se ao grupo a tarefa de indicar os diferentes ân gulos sob os quais êle deve ser encarado, e adotar a solução que lhe parecer mais apropriada.

b) O caśo é descrito e para êle são prescritas várias soluções que o grupo deverá analisar e comparar, com o objetivo de eleger a solução mais conveniente.

c) () caso é relatado já com a solução que para êle foi adotada, a fim de que o grupo critique essa solução, para aceitá-la ou rejeitá-la, fundamentadamente.

O caso, a exemplo dos métodos participativos e de envolvimento, por ser atraente para o aluno e atender a certas condições psicológicas do processo da aprendizagem pode, se não fôr usario com o necessário critério, levar ao desinterêsse por outros métodos, cujas virtudes êle é incapaz de suprir. O uso exclusivo do método do caso conduz, na maioria das vêzes, a uma aprendizagem fragmentária e ao desperdício de outros recursos mais adequados à sistematização do ensino. 